\title{
APPLICATIONS OF ELECTRONICS IN SMALL SCALE INDUSTRIES FOR COUNTING PRODUCTS
}

\author{
J. Uma Maheswari ${ }^{1}$ and S.Kavitha ${ }^{2}$ \\ ${ }^{1,2}$ Assistant Professor, Department of Electronics And Instrumentation Engineering, Kamaraj College of Engineering \& \\ Technology, India \\ Email: $\left\{{ }^{1}\right.$ anishmakilan@gmail.com, ${ }^{2}$ kavisuresh90@gmail.com $\}$
}

\begin{abstract}
In a developing country like India, the task and impact of small-scale industries is very noteworthy towards poverty abolition, rural progress and building regional balance in augmentation and growth of various development activities. Small-scale industries have enormous potential to create or take up the modernism. Many systems and practices that have major impact on the effectiveness of the counting products produced remain under- focused. This paper will help small scale industries setup a simple method for counting products in an exact count which is ready for dispatch. In this paper, the number of products ready to dispatch is quantified and number of products to be dispatched are also controlled using basic electronic components in the small scale industry is documented. Thus, it is possible to execute modernization of various small scale industries to strengthen their production capability.
\end{abstract}

Key Words - Modernization, Dispatch, Counting

\section{Introduction}

The small scale industries make available ample opportunities for the enhancement of technology and technology in turn, creates circumstances encouraging to the improvement of small units. The entrepreneurs of small units take part in a strategic role in profit-making new inventions and products. It also aids the transfer of technology from one form to the other form. As a result, the capital yields the benefit of better technology. Small scale entrepreneurs are not interpreted to the modern technology. Moreover, they lack in necessary resources to update or modernize their plant and machinery. Due to outdated methods of process used, they are dealt with the troubles of less production in substandard quality and that too at higher cost. So, they are not capable to compete with their better equipped challenger operating modem large scale units. Here the counter circuit is used to count the number of bottles produced and ready to dispatch in mineral water plant. The counter circuit consists of simple electronic components like LED and LDR whose output is connected to circuit to count and display as digital values.

\section{Methods and Materials}

\subsection{Light Dependent resistor}

A light-dependent resistor (LDR) or photocell or photo resistor is a light-controlled variable resistor. The resistance of a LDR reduces with rising incident light intensity (i.e.) it exhibits photoconductivity. A photo resistor can be affected by light receptive sensor path and illumination controlled circuits. A photo resistor is made of a high resistance semiconductor. With no light, LDR has high resistance value in the order of few mega ohms (M $\Omega$ ), while in the light, LDR has low resistance value in the order of few hundred ohms. The working principle of LDR is the resistance of photo resistor will vary with the variation in the intensity of ambiance light. In a dark condition the LDR resistance is about $10 \mathrm{M} \Omega$ and in an illuminated condition is about $1 \mathrm{~K} \Omega$ or less. LDR is made of semiconductor material cadmium selenide. In the dark or muted light, free electrons produced is moderately little amount from the LDR. This little amount of free electrons is responsible for carrying the electrical charge. Hence, when the light is dim, LDR becomes a poor conductor, or LDR can have a high resistance in the dark condition. At the bright light, free electrons produced is comparatively higher amount from the LDR. This higher amount of free electrons is responsible for carrying the electrical charge. Hence, when the light is bright, LDR becomes a good conductor, or LDR can have a low resistance in the bright condition [5]. In a nutshell, if light is made to fall on the LDR goes above a certain frequency, the semiconductor material in the LDR absorbs photons and provides bond electrons to adequate power to cross the energy gap. The movement of free electrons resulting conduction of electricity, thereby resistance of LDR reduces.

\subsection{Light Emitting Diode}

LEDs are small light bulbs that insert into an electrical circuit without difficulties. LED is a semiconductor made diode which releases light when it is forward biased. When above threshold voltage is applied across the diode terminals, electrons are able to recombine with holes and start to emit energy in the form of light. In contrast to the common incandescent bulbs, they don't have a filament that will destroy by fire, and they don't acquire heat. They are lighted up exclusively by the movement of electrons in a semiconductor material. 


\subsection{Comparator}

The LM358 comprises of two inbuilt, high gain operational amplifiers which were intended specially to function from a power supply over a large range of voltages. Working from divided power supplies is also feasible. The LM358 is accessible in a chip sized with surface mounting technology package. Fig 1. shows the pin details of LM358.

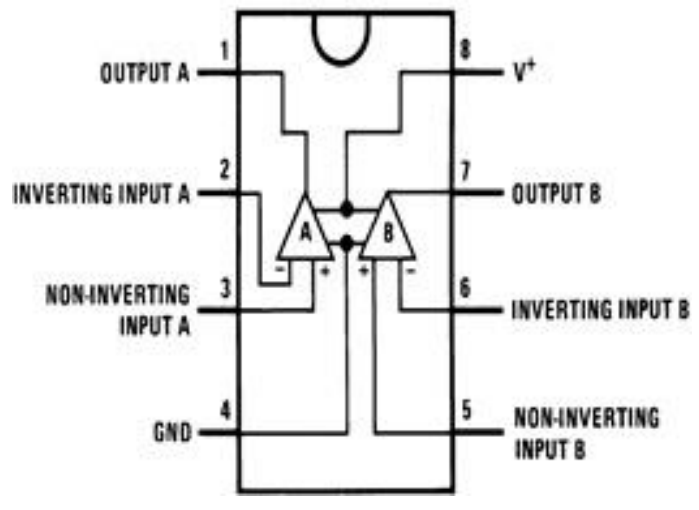

Fig. 1 Pin details of LM358

The LM358 series are op amps which operate with single power supply voltage, have true-differential inputs, and remain in the linear mode with an input common-mode voltage of $0 \mathrm{VDC}$. At $25^{\circ} \mathrm{C}$ amplifier function is potentially down to a lowest supply voltage of 2.3 VDC.

\section{Implementation}

In the small industries counting the number of products produced will be implemented with the help of LED, LDR, $5 \mathrm{~V}$ power supply, Interfacing unit, computer, relay. The control algorithm is stored in the computer to display the number of products dispatched/produced and also to take the control action whenever products to be dispatched exceed the desired value or target. Fig. 2 shows that block diagram of counting and controlling the dispatched products.

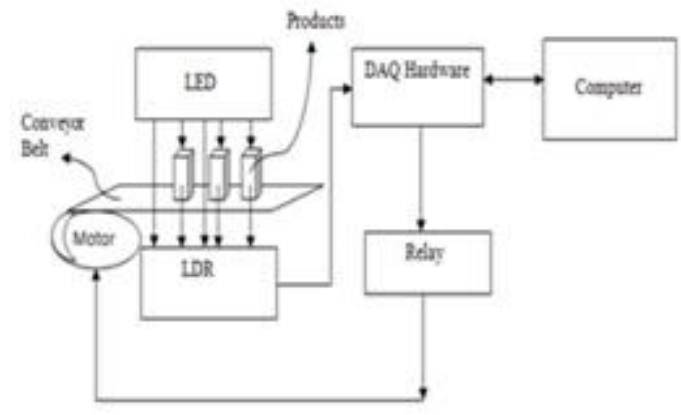

Fig. 2 Block Diagram for counting and controlling number of products to be dispatched

Generally, IR sensors are used for detection of products/persons, which is costlier than LED and LDR and also the output produced by the IR sensor is very less [2], when the path is blocked or not blocked, which is difficult for the processor to identify, but the LED and LDR circuit gives greater deflection of about 2.5 to 3.5 volts to detect the presence of product.

The LED and LDR are the basic electronic components which are used to detect or sense the product. Depending upon the output voltage the product count is incremented in the counter. The LED and LDR arrangement is placed at both the sides of conveyor belt or path through which packed products/mineral water bottles are passing.

The LED and LDR are connected as shown in fig 3. LDR is connected as one of elements in voltage divider bias network [4]. Whenever packed products cross between LDR and LED, due to the blockage of light path, a voltage drop across the LDR is obtained. When the packed product crosses between LDR and LED the light path is blocked and hence the resistance of LDR is high thereby voltage drop across the LDR is high and vice versa. This voltage is fed to the comparator circuits. The comparator compares the voltage value from the detecting unit with reference value.

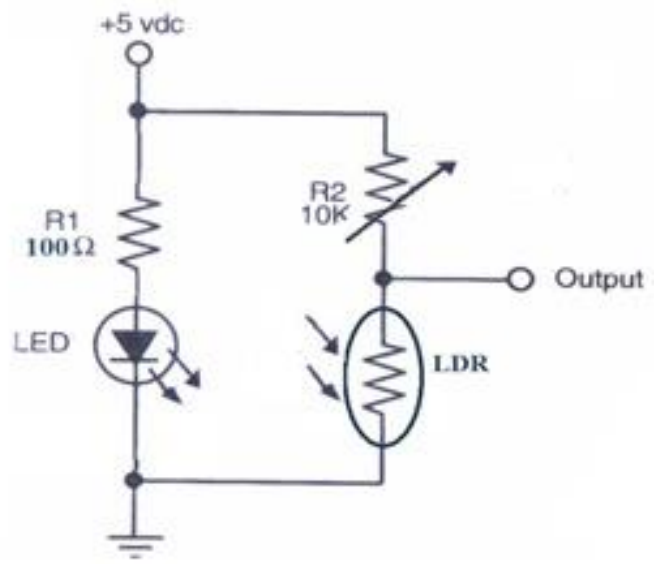

Fig. 3 LDR \& LED Arrangement

If detector output is greater than reference value then comparator produces the output as otherwise zero. The reason for comparison is that to ensure that product is identified precisely. The comparator output is given to the controller (PC) through DAQ hardware for monitoring and controlling. The control programming is done with LabVIEW software. LabVIEW programs are labeled as virtual instruments, or VIs, since their outward show and function replicates the physical instruments, such as signal generators and $\mathrm{CRO}$ [9]. LabVIEW is a inclusive tools for acquire, analyze, display, and storing data. In LabVIEW, user interface can be built and programming is done in block diagram window. Output can be displayed in front panel window using controls and indicators. Controls are knobs; push buttons, dials, and others input mechanisms. Indicators are graphs, LEDs, and other output displays. Real time data are communicate with processor through hardware such as DAQ, vision, and motion control devices, as well as GPIB, PXI, VXI, RS232, and RS485 instruments. 
The DAQ hardware is a tool used to interface the real time sensor output with the Computer, so that the program is able to process the sensory outputs and give control signal [1]. The DAQ hardware used in this project is NI USB 6009 which is a portable device. It can acquire eight different analog inputs and it gives out two analog outputs [10]. The input to the DAQ hardware should not exceed +or- $5 \mathrm{~V}$ or else the DAQ may get damaged. The DAQ output will not be sufficient to drive motor to block/allow the bottle to dispatch as the current rating will be only $20 \mathrm{~mA}$. Hence the DAQ output is given to base of the npn transistor which acts like switch. The collector terminal of npn transistor is connected to one of the Relay pin. Hence whenever DAQ gives output, motor will be switched ON/OFF, based on the number of bottles dispatched. Here the relay used is an electronic component that toggles either turn on or off conveyor belt motor when a small external voltage is passed through control terminals. Relay responds to a proper control signal, in turn switches power to the motor thereby run/stop the conveyor belt driven by the motor .

\section{Results and Discussion}

41. Simulation Results for hardware part

In order to verify that the proposed system can be practically implemented, simulations were performed by simulation software. The voltage drop is noted whenever the product crosses between the LED and LDR. The product presence is validated with the help of comparator. When light path is not obstructed by the product voltage drop across LDR is $0.75 \mathrm{~V}$ and light path is obstructed by the product voltage drop across LDR is $3.92 \mathrm{~V}$ provided with LDR and LED is $5 \mathrm{~V}$.

Table: 1 Output for product detection circuit

\begin{tabular}{l|c|c|}
\hline \multicolumn{1}{|c|}{ Condition } & $\begin{array}{c}\text { LED \& LDR } \\
\text { output } \\
\text { in Volts }\end{array}$ & $\begin{array}{c}\text { Comparator } \\
\text { output } \\
\text { in Volts }\end{array}$ \\
\hline $\begin{array}{l}\text { When light Path } \\
\text { is not obstructed } \\
\text { by the product }\end{array}$ & 0.75 & 0 \\
\hline $\begin{array}{l}\text { When light Path } \\
\text { is obstructed by } \\
\text { the product }\end{array}$ & 3.92 & 3.84 \\
\end{tabular}

For the validation of presence of product, reference voltage is set as $1.5 \mathrm{~V}$. If the product is sensed then output from the comparator is $0 \mathrm{~V}$. If the product is not sensed then output from the comparator is $3.84 \mathrm{~V}$. These results are tabulated as shown in the table 1 . Before doing practically, the comparator output is simulated using simulation software and output is checked. Similarly, the output from DAQ hardware is also given to the control unit is verified and

ISSN (Print): 2456-6411 | ISSN (Online): 2456-6403 validated using simulation software. The simulated results are shown in the fig. 4 and 5 respectively.

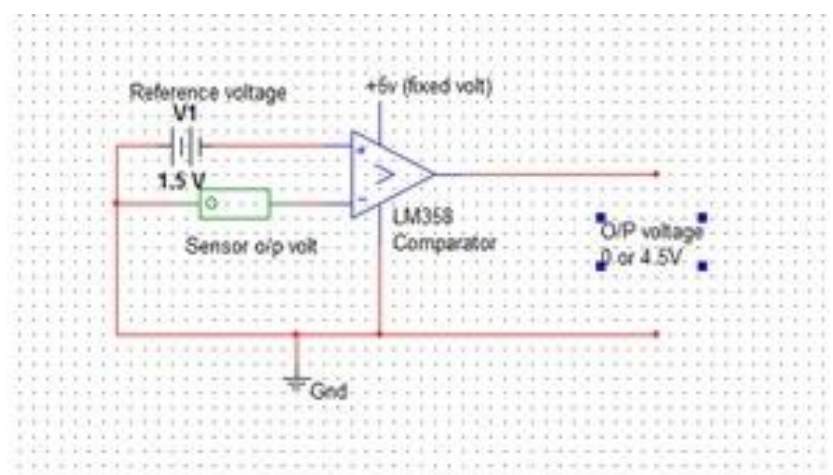

Fig. 4 Simulated Output for Comparator circuit

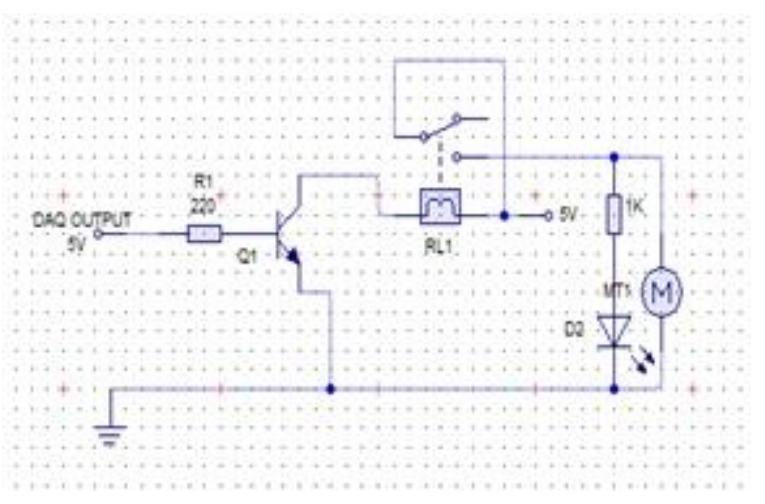

Fig. 5 Simulated Output for Comparator circuit

\subsection{Simulation Results for software part}

The input from LED and LDR unit is fed to LabVIEW through NI USB 6009 DAQ hardware. The fig.6 describes

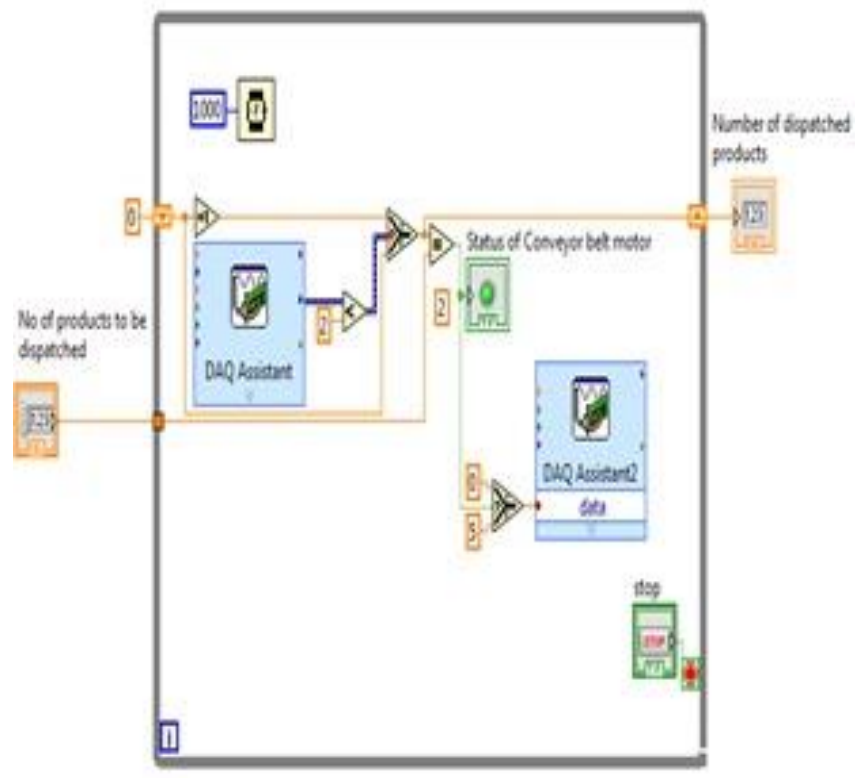

Fig. 6 Implementation using LabVIEW 
that output from counter circuit is compared with a reference value of $2 \mathrm{~V}$. If the value of output exceeds the reference value then the presence of product is confirmed and count value will be increased by one otherwise the count value remains same. In the mean time the output of counter circuit is compared with number of products to be dispatched. If output from the comparator circuit is high then voltage signal is generated and is given to the relay unit through DAQ hardware to stop the running condition of conveyor belt driven by the motor.

Here, the product to be dispatched is taken a target value as 100 , counter continuously counts the number of products dispatched and it is displayed in the front panel and also status of the conveyor belt motor. In figure 7a. green color indicates that the conveyor belt motor is running. Generally, the conveyor belt is used in industry at dispatch section over which the products are passing In figure $7 \mathrm{a}$, shows that the number of products to be dispatched is 100 and the number of dispatched products is 50 . The counter continuously counts the number of dispatched products also the motor continues to run till the dispatched product count reaches 100. If the number of products to be dispatched is not equal to the number of dispatched products then relay is not activated and hence the motor running.

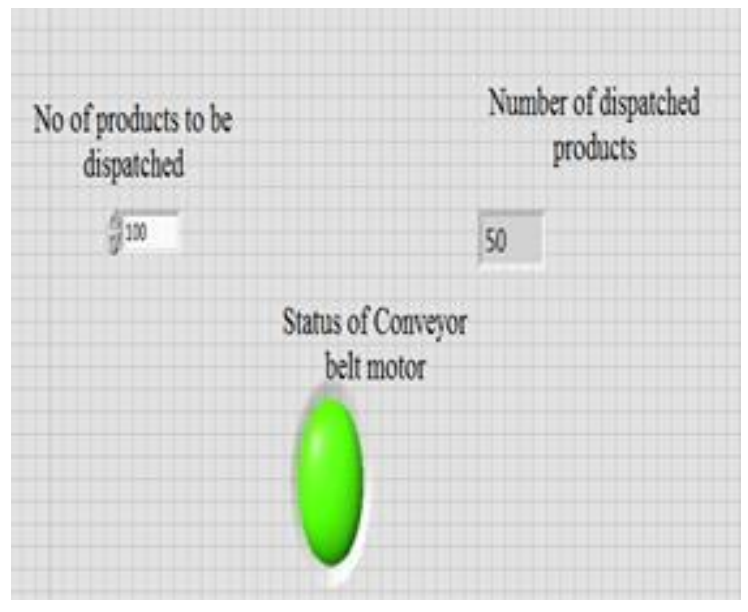

Fig. 7a Front Panel

In figure $7 \mathrm{~b}$. red color indicates that the motor is stopped and hence the products are blocked from sending out for packing or dispatching. This figure shows that the number of products to be dispatched is 100 and the number of dispatched products is 100 . The number of products to be dispatched is equal to the number of dispatched products then relay is activated and hence the motor is stopped.

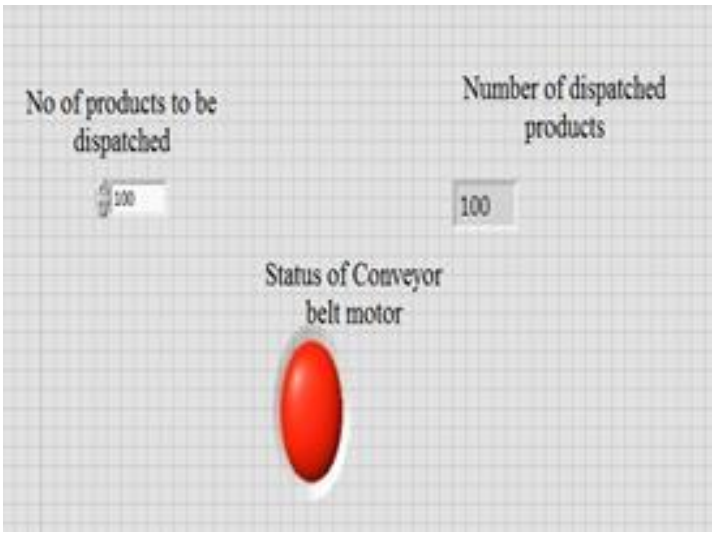

Fig. 7b Front Panel

\section{Conclusion}

The implementation of this method will give a new approach for modernization of small sale industries to count the number of packed cartons of spices, garments, mineral water bottle, paint containers etc., in the outlet/dispatch unit with the use of simple electronic components. Thus the technical intervention in small scale industries promotes not only the industries but also economy of the developing country.

\section{References}

[1] Mohamed SB, Minhat M, Kasim MS, Adam MHM, Sulaiman MA, Rizman ZI, "An intelligent lighting control system (ilcs) using labview", J. Fundam. Appl. Sci., 9(2S), 2017, 602-615.

[2] Maharani Putri1, Solly Aryza, "Design of security tools using sensor Light Dependent Resistor (LDR) through mobile phone", International Journal of Innovative Research in Computer and Communication Engineering Volume - 4, Issue - 10,2018, 168-173.

[3] User Guide and Specifications NI USB-6008/6009, http://ni.com/manuals.

[4] Atharva Dingore, Darshan Salunkhe, Hritik Kalantri, "Light Dependent Resistor Product Separator", International Journal of Innovative Research in Science, Engineering and Technology (IJIRSET), Volume 9, Issue 5, May 2020.

[5] http://www.ni.com/pdf/manuals/373427j.pdf

[6] Ms. M. Kokilavani, Dr. A.Malathi, "Smart Street Lighting System using IoT", International Journal of Advanced Research in Applied Science and Technology, ISSN: 2456-1959 Vol.3, No.11, November 2017.

[7] Juan Román-Raya,Isidoro Ruiz-García,Pablo Escobedo,Alberto J. Palma,Damián Guirado andMiguel A. Carvajal, "Light-Dependent Resistors as Dosimetric Sensors in Radiotherapy", Sensors 2020, 20(6), 1568; https://doi.org/10.3390/s20061568.

[8] Aishwarya.N. Patil, Ashwin Tripathi, S. A. Fanan "Intelligent Street Light System using Arduino UNO", 
IJESC, Volume 7, 2017.

[9] Jassada Sarasook and Chaiyapon Thongchaisuratkrul, "An Implementation of Illuminance Meter using Light Dependent Resistor Integrated with Labview Program", Academic Journal of the Faculty of Industrial Technology Lampang Rajabhat University,2018.

[10] Kalathiripi Rambabu, P. Aravind Sai, E. Samuel, P.N.V.S.M. Varma, M. Sumanth Reddy, "Monitoring and Controlling of Home Security System using IoT and LabVIEW" International Journal of Control and Automation, 13(4), 2020, 596 -605 .

[11] Mohamed SB, Minhat M, Kasim MS, Adam MHM, Sulaiman MA, Rizman ZI, "An intelligent lighting control system (ilcs) using labview", J. Fundam. Appl. Sci., 9(2S), 2017, 602-615.

[12] Aishwarya.N. Patil, Ashwin Tripathi, S. A. Fanan "Intelligent Street Light System using Arduino UNO”, IJESC, Volume 7, 2017.

[13] Ms. M. Kokilavani, Dr. A.Malathi, "Smart Street Lighting System using IoT", International Journal of Advanced Research in Applied Science and Technology, ISSN: 2456-1959 Vol.3, No.11, November 2017.
[14] Jassada Sarasook and Chaiyapon Thongchaisuratkrul, "An Implementation of Illuminance Meter using Light Dependent Resistor Integrated with Labview Program", Academic Journal of the Faculty of Industrial Technology Lampang Rajabhat University,2018.

[15] Maharani Putri1, Solly Aryza, "Design of security tools using sensor Light Dependent Resistor (LDR) through mobile phone", International Journal of Innovative Research in Computer and Communication Engineering Volume - 4, Issue - 10,2018, 168-173.

[16] Kalathiripi Rambabu, P. Aravind Sai, E. Samuel, P.N.V.S.M. Varma, M. Sumanth Reddy, "Monitoring and Controlling of Home Security System using IoT and LabVIEW" International Journal of Control and Automation, 13(4), 2020, 596 - 605.

[17] Atharva Dingore, Darshan Salunkhe, Hritik Kalantri, "Light Dependent Resistor Product Separator", International Journal of Innovative Research in Science, Engineering and Technology (IJIRSET),Volume 9, Issue 5, May 2020.1

[18] Juan Román-Raya,Isidoro Ruiz-García,Pablo Escobedo,Alberto J. Palma,Damián Guirado andMiguel A. Carvajal, "Light-Dependent Resistors as Dosimetric Sensors in Radiotherapy", Sensors 2020, 20(6), 1568; https://doi.org/10.3390/s20061568

[19] http://www.ni.com/pdf/manuals/373427j.pdf

[20] User Guide and Specifications NI USB-6008/6009, http://ni.com/manuals. 